\title{
The pressure of technological innovations in meeting and event industry under the COVID-19 influence
}

\author{
Mg. oec. Galina Bukovska \\ Vidzeme University of Applied Sciences \\ Valmiera, Latvia \\ galina.bukovska@va.lv
}

\author{
Mg. oec. Anda Mezgaile \\ Vidzeme University of Applied Sciences \\ Valmiera, Latvia \\ anda.mezgaile@va.lv
}

\author{
Dr. geogr., assoc. prof. Andris Klepers \\ Vidzeme University of Applied Sciences \\ Valmiera, Latvia \\ andris.klepers@va.lv
}

\begin{abstract}
The innovation in technologies is one of the principal external forces that has a direct influence on the competitiveness of the meeting and the event industry. Therefore, implementation and adaptation of the new technological solutions in it has continuously followed the innovations in technological industry itself. However, the COVID-19 pandemic with the following lockdowns has pushed the industry to search for new technological alternatives to innovate their way out of the crisis in a very short time period. This was the first time when all the events from small family celebrations and weddings up to the international conferences and product launch events, have had to be cancelled or postponed or could have happened only to a very limited extent and under strict regulations excluding any larger gatherings of people. The event providers were forced to find new solutions to continue their business and not to hibernate with the minimum downtime allowance granted by the state to the employees. Technologies supporting various types of online events became the ultimate digital tool that helped event planners to execute projects from the beginning to the end after March 2020. The purpose of the research is to explore these changes in the usage of the technologies in meetings and events organized in Latvia caused by COVID-19. The quantitative analysis of the structural on-line survey data provides insights on what extent technology adoption in meetings and events businesses has been before and during COVID-19 and what are the future prospects supplemented by the in-depth interview data and qualitative analysis. Authors are investigating what is the amount of virtual and hybrid events organized in Latvia before and after COVID-19, what platforms the organizers used for their virtual events, what is the level of satisfaction and what kind of challenges the event organizers faced in the process of adoption of new technologies. The results of this research not only state the current position within the framework of the industry, but also enriches discussion about the adoption of new technologies to innovate the way out of the crisis and could help in some degree to strengthen the productivity growth in a long term perspective.
\end{abstract}

Keywords - meeting and event industry, innovation, technology, COVID-19, business tourism

\section{INTRODUCTION}

The meeting industry could be named as one of the fastest growing segments of the global economy as namely all the world's largest industries are furthered by it [1]. Despite meetings have always been there and people gathered for discussing communal interests since ancient times, the interest to attract contemporary business events to a various host destinations is argued with higher expenditures by business travellers, possibilities to utilize visitor-relevant facilities over a longer period than the traditional holiday peaks mitigating seasonality and the amenities that a city or a country can offer for that type of events co-benefit for residents and enhance attractiveness of a destination's even wider [2]. The First congress took place in Vienna in 1814-1815 to discuss the re-organization of Europe after the Napoleonic Wars [3]. The expansion of government organizations, the growth of multinational corporations, the development of professional associations, new approaches to human resource management, and the implementation of new marketing and sales techniques, stimulated the growth of meeting and event industry since 1950-ies [4], [5].

The meeting industry as a term was introduced in 2006 by a number of organizations including the International Congress and Convention Association (ICCA), Meeting Professionals International (MPI), Reed Travel Exhibitions and the United Nations World Tourism Organization [6]. This term includes business or professional meetings, conferences, congresses, fairs exhibitions [7]. The international associations such as ICCA, UIA, MPI have different categorization of meetings. The meetings could be divided into local and international with the number of 
participants from five to thousands, with different number of dates and different volume of countries participating. Each association is regulating their categories depending on association and destination specification. In the academic field business tourism and meeting \& events industry categorization has been examined increasingly by Arcodia and Robb [8], Swarbrooke and Horner [9] providing predominantly types of meetings, events and business travel and listing major products and developing further to the well-defined typology by Getz [10], [11] and McKercher [12]. The Evolution of technological adaptations in the sector has been comprehensively analysed by Buhalis and Law [13] and Navio-Marco et.al. [14].

As per report of the Union of International Associations (UIA) [15] the total amount of meetings in 2019 was 12 472 in 161 countries and in 1251 cities. According to the International Congress and Convention Association (ICCA) the number of international association meetings doubled every 10 years [16]. The 2019 figures confirm this raising trend, the total number of meetings is high, growing to 13254 with 317 more events compared to the year 2018 [16]. Europe continues to have the largest share of the association meetings market, hosting $53 \%$ of all meetings held in 2019 [16]. The meeting industry became a visible actor on the tourism map of individual countries and continents [17]. Getz [10] considered events as important motivator of tourism, and highlighted its role in the development and marketing of most destinations. Getz argues that it was only a few decades ago that "event tourism" became established in both the tourism industry and in the research community, so that subsequent growth of this sector can only be described as spectacular [18].

The COVID-19 pandemic suddenly stopped the classical solutions and highlighted the new norms for meetings and events industry. The physical distancing forced the meeting organizers to show agility and resilience, in "panic creativity" conditions they have no other choice than to accept and invest into new formats of meetings and events. It is crucial to understand if the investments made will guarantee the efficiency and stability and will be paid off in future. COVID-19 vast impact on the industry dynamics has been analysed avalanching recently e.g., as researching impact on the global tourism industry, by Li et.al. [19] underlying effects on tourists' behavioural patterns, Wut et.al. [20] broadening it to the crisis management research, Kaushal and Srivastava [21] providing general managerial recommendations or as Breier et.al. [22] investigates concrete business model innovations as a way out of the crisis or MICE sector relation to the destination performance. Virtual and hybrid technologies created the paradigm of the new era of events, opened the opportunities for delegates' inclusivity, reduction of environmental impact, increase engagement and interactivity and financial accessibility, but at the same time raised up new challenges of minimizing digital exclusion, providing technical support, facilitating opportunities for networking and supporting physical wellness of the delegates [23].
The researches of several medical conferences in 2020 provides clear evidence that changes in medical meetings will have place and live activities need to consider multiple approaches that include technology [18], [24], [25], [26], [27], [28]. Medical community and event organizers already are implementing and looking for new solutions and formats supported by information and communication technologies. Margolis presented the concept of Extended Congress [24]. This concept leverages the extension of time, space and languages of scientific meeting. This concept allows to reach larger audience, increase accessibility, facilitate the networking and engagement.

Although the COVID-19 pandemic forced the event organizers to ensure significant investments and in short time to adopt their meetings, congresses, conferences, exhibitions to virtual and hybrid formats, the concept of virtual events is not new. The World Wide Web was used since 1993, one of the first scientific conferences ECCC (Electronic Conference on Computational Chemistry) was organized in 1995 and followed by other conferences and events [23]. The recent decades show that meeting industry was changing rapidly by implementing on-line registration systems, event supporting applications, virtual platforms and live streaming. The most popular meeting technologies introduced by a survey undertaken by the International Association of Conference Centres between 2012 and 2017 were conference applications, social media campaigns, audience participation applications, live event streaming, virtual participation [3] Webinars have received positive evaluations for quality, value, and relevance already since 2012 and have been used for remote training, courses and education [29]. The researches of years 2020 and 2021 show that the implementation of virtual platforms, which bring communities together in three-dimensional virtual spaces, video conferencing and media sharing tools enable participants to experience the presentations and to interact with fellow delegates [30]. The social media, online platforms and apps for meetings could be integrated into future meetings and congresses [31]. Virtual spaces and interactions can completely reform not only the events, but also education, traveling and working [32]. Therefore, the authors started structured research about challenges and opportunities and of virtual and hybrid meetings, the usage of various innovative tools implemented during the period of COVID-19 investigating dynamics of changes and looking forward for the future application of technologies in meetings and events.

\section{MATERIALS AND METHODS}

The aim of the research is to explore the changes in the usage of technologies in the meetings and the events organized under the influence of COVID-19. The subject of this study is the usage of technologies. The object of this study are the regional and the international events which took place in Latvia in 2019 and 2020. The event is defined as the regional (with participation of delegates from Latvia, Lithuania and Estonia) or the international level conference, congress, seminar or forum with number of participants not less than 50 in Riga and not less than 25 in 
Environment. Technology. Resources. Rezekne, Latvia Proceedings of the 13th International Scientific and Practical Conference. Volume 2, 44-50

the regions of Latvia. Limitations of this research is a short time period to perform questionnaires and COVID-19 restrictions which caused many service providers a complete closure of a company or a temporary closure of a business and accessibility of the respondents.

The contemporary Latvian meeting and event industry was rooted in the beginning of 1990-ies, after Latvia renewed its independence and the border opening with the West put the beginning of the international business tourism to the country re-focusing from the previous planned economy traditions to the open market economy. Unfortunately, it is limited by the destination capacity, main infrastructure (venues, international chain hotels with the meeting room capacity) and the airport being located in the capital city Riga and nearby town Jurmala, other cities have limited amount of meeting infrastructure and are not primary destinations for the regional and the international events. Most of the service providers and the event organizers are located in the capital city Riga located in the middle of the three Baltic states (Estonia, Latvia and Lithuania) and use its infrastructure.

To achieve the aim of the research, the integrated research method (i.e., the triangulation method) was used, which refers to the use of more than one method of data collection for the same objective to assure validity. A structured online survey (quantitative research method) investigates the usage of technologies in years 2019 and 2020 were developed. For all the most important players of meeting and event industry within the state were given the opportunity to respond. The primary data was collected by two questionnaires:

a) the service provider's questionnaire, where the study audience were Professional Conference Organizers (PCO), Destination Management Companies (DMC), Event Agencies, PR agencies, Hotels with conference facilities, Event Technical Equipment Providers, Congress Centres, Venues with conference facilities;

b) the event organizer questionnaire, where the study audience were Associations, other public or non-profit organizations, government or municipality organizations, education organizations, entrepreneurs.

The survey was distributed by platform visidati.lv, through the professional meeting and event industry associations, Latvian Investment and development agency, social media (Facebook, LinkedIn) and by direct mailing to various industry associations. The a) questionnaire consisted of 34 questions, answers to all the questions were mandatory, otherwise the survey could not have been proceeded. The b) questionnaire consisted of 29 questions, answers to all the questions were mandatory, otherwise the survey could not have been proceeded. Both surveys were divided in three main sections: I. A The Characteristics of the Respondents; II. The Characteristics of the Events and Delegates; III. Technology Usage. The survey was anonymous. IP restrictions were implemented; one IP address could only complete the survey once. All the data were collected within the VisiDati.lv system, and only authors could access this data, all IP addresses and responses were removed from the publicity.
Descriptive research methods were used in this study. A total of 75 responses were collected; after cleaning the data, 70 responses were found usable for the analysis purpose. The quality analysis method by using MAXQDA program was applied to both questionnaires' respondents' comments analysis. For Quantitative research analyses MS Excel was used.

The a) questionnaire was disseminated primary through the professional associations: Latvia Convention Bureau, Latvia Hotels and Restaurant Association, Association of Latvian Travel Agents and Operators, Latvian Investment and Development Agency, Latvian Event Producers Association, Latvian Event Venue Association. The b) questionnaire was sent to various Latvia represented industry professional associations for the distribution to their members, total 226 associations.

The expert interview was conducted with Neil Kalnins, the organizer of "5G TECHRITORY" conference (https://www.5gtechritory.com/). The event was investigated as a case study with the aim to look deeper into the event the technologies transformation from 2019 to 2020. The two "5G TECHRITORY" events were analysed from the following positions: event venue, number of participants, number of countries participating, number of speakers, expenses, the time spent for organization of the event, number and competence of staff, engagement and interactivity, the usage of technologies.

\section{RESUlTS AND DisCUSSIONS}

\section{A. The Characteristics of the Respondents}

The total amount of participated in the survey $(n=70)$ was mostly represented by the event organizers (61.4\%), located in Riga (60.4\%). The service providers participated in the survey make $38.6 \%$, the same as the event organizers mostly located in Riga (51.8\%). Most of the respondents have long-term experience, $60 \%$ are engaged in the international events organization for more than 10 years.

\section{B. The Characteristics of the Events and Delegates}

Conferences and seminars are the main types of the events organized $-81 \%$, forums $-36 \%$, congresses are also placed in, but with lower intensity - 31\%. Discussions, lectures, social events, visits, exhibitions, etc. were marked as other events. The average number of the events organized by associations, government and municipality organizations, education organizations and corporates vary mostly from 1 to 5 events per year $-63 \%$, most of the service providers maintain more than 10 events per year $89 \%$ of respondents. The number of events during COVID19 pandemic decreased for both the event organizers by $18 \%$ and the service providers by $29 \%$, most of the events were forced to be postponed to the year 2021 or 2022.

The number of the delegates per one event decreased in 2020. Most of the events organized before the COVID-19 varied in between 51 to 250 participants per event, the number of this type of events decreased for 10\% in 2020. This could be explained by the numerous COVID-19 restrictions. However, in separate cases as "5G TECHRITORY” the number of the participants comparing 
with 2019 doubled, from 700 participants in 2019 up to 2000 participants in 2020 .

The country of the origin of the participants expanded in $8 \%$ of cases, in $61 \%$ of cases the country of the origin narrowed down, and nothing changed in $31 \%$ of cases. $52 \%$ of the event participants were from different countries in Europe, 36\% from different countries all over the world and $12 \%$ - only from the Baltic States. The place of event before restrictions was $92 \%$ on site, but it decreased and $65-75 \%$ of 2020 events were online or hybrid. Despite the fact that significant number of the events were organized during COVID-19 restrictions, all the service providers mentioned the turnover decreased up to $50 \%$ or $70-90 \%$.

\section{Technology Usage}

The restrictions caused by COVID-19 since March 2020 forced $69 \%$ of the meetings to be transferred into virtual or hybrid environment. The survey shows that most of the respondents already used the developed platforms, such as Zoom, Webex, MS Teams, some of the organizations implemented their own original platforms, in some cases as with "5G TECHROTORY" several platforms (Webex and specially designed local platform Attend.me) were integrated together (Fig.1).

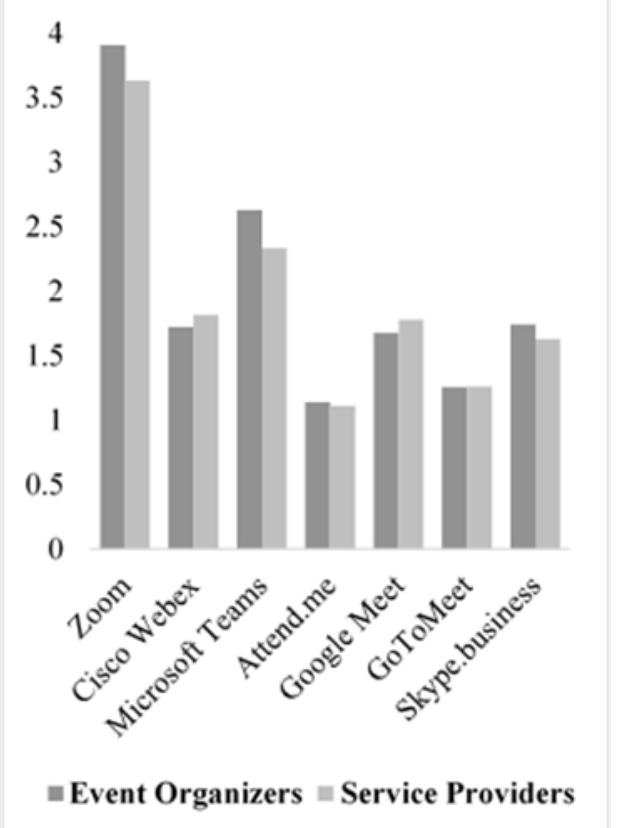

Fig. 1. Used online platforms for events (I - not at all, 2 - a little, 3 - moderately, 4- a lot, 5 - in all events without exception).

\section{Fig. 1. Used online platforms for events}

The respondents were asked to evaluate the intensity of the usage of 16 types of technologies before COVID-19 restrictions in 2020 and their desire to operate the same technologies in the future. The results showed (Fig.2) that such technologies like the online registration, the event website, the multimedia projection, the event video filming, the social media channels are familiar to the respondents and they used them moderately. The usage intensity of the above-mentioned types of technologies increased in 2020 and the list was added by event virtual platform, event live streaming, event online analytics, onsite data collection and webinars.

The Respondents plan to continue to operate most of the technologies they implemented and plan to do it more intensively than in 2020, specially related to the online registration, event webpage, event virtual platform, event live streaming, webinars, event online analytics, on-site data collection and social media channels. Other technology solutions named were Kahoot, Sli.do, Whatsap, Youtube, Facebook live videos, remote voting, etc. The organizer of "5G TECHRITORY", Neil Kalnins in his interview pointed out that the online analytics was one of the most valuable benefits for conference organizers, providing very precise data and delivering the detailed information about everything what has happened during the event. Another success of the event was the usage of the set of platforms. This approach ensured possibility to integrate Webex communication platform and to create three different stages of the conference and virtual expo venue. Unlike 2019, where a static website was developed for the event, 2020 technologies allowed to integrate the web page into the platform and provided the delegate engagement already from the first step. Entering the conference platform, the delegates had the choice to choose which stage they want to stay at, they could move from stage to another stage or enter the virtual expo. This brings forth the attention and interest of the participants and overcome the time difference.

The results of the survey show that the meetings and the event organizers and the suppliers in most cases positively evaluate the usage of the technologies in the organization process of the event (Fig.2). According to $81 \%$ of respondents they agree that future events will take place in hybrid format, but likewise they do not exclude the existence of fully virtual meetings and onsite meetings, which create the specific atmosphere and positive memories.

Overall, the respondents are satisfied with the new technologies, they feel safe or almost safe operating them, they consider that technologies could save time and financial resources, increase the engagement and comfort, expand the opportunity to invite and hear rare-accessible lecturers. The Service providers point out that their employees have medium or good skills in work with technologies, but only Professional Conference Organizer rates employee skills as "very good". Among the main challenges the respondents pointed out the problems connected with the Internet - $20 \%$ of the respondents mentioned lack of the Internet speed and the signal coverage. The respondents most worry about the lack of the experience and the skills, as well as uncertainty about the technical equipment they have. The following skills and knowledge they consider should be improved: digital skills, knowledge about virtual platforms, human behaviour and its prediction, as well the respondents consider as need to exchange and share experience between colleagues. 


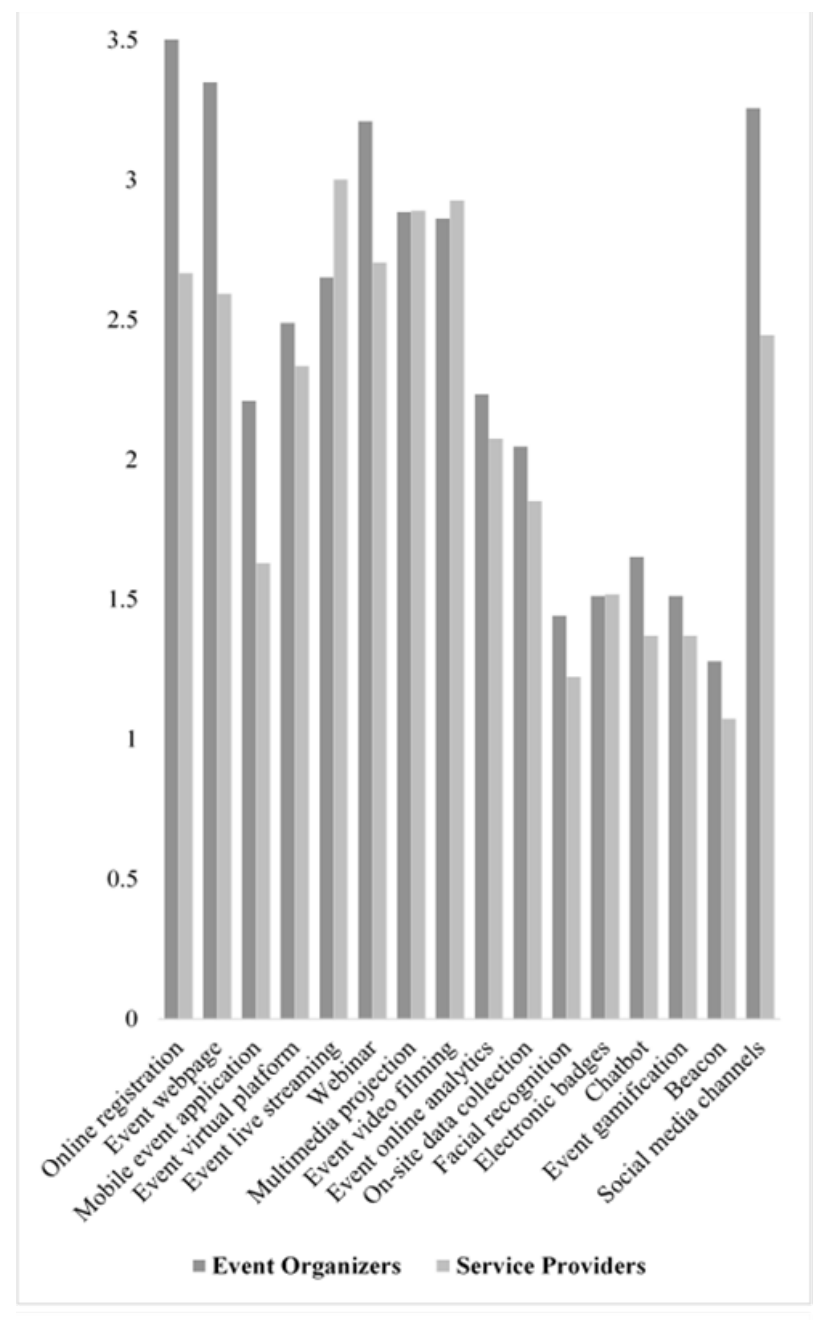

Fig. 2. Used technological solutions for events in 2020 ( $I$ - not at all, 2 - a little, 3 - moderately, 4- a lot, 5 - in all events without exception).

Fig. 2. Used technological solutions for events

This study contributes to the Getz [11] statement about the future research direction needs regarding wider discussion on the environmental impact from the industry pointing out advantages of distant online events specific role. But it stays in the contradiction to the participant traveller raising trend to accumulate more authentic leisure experiences combined with the business tourism. This study demonstrates adoption of various technological advances as the solution for the crisis management performed by the meetings and the event's organisers similarly as Hajibaba at al. [33] have suggested analysing the crisis management in regard to prevention and preparedness strategies facing the business travel segment, pointing to the sector which may recover sooner in the post crisis era. However, the challenge to find systematic ways out of the crisis for the entire supply chain stays open as digital solutions are not helping for many location-based services. According Wut et al. [20] there should be clear concerns about what are the effects of crisis prevention and preparedness in the future for the international tourism. This study shows clearly individual adoption of the crisis management by various stakeholders, but there is lack of data and discussion in this research about the systematic tools to support the recovery of the whole industry. Although, what will be the financial concerns and productivity issues in a long-term of these rapid innovations caused by COVID-19.

Summarizing the main part of the results and answering the research question: what are the changes in the usage of technologies in the meetings and the events organized under the influence of COVID-19, the extremely rapid adaptability of entrepreneurs and the leap in technological development in the application of everyday developments should be highlighted within a period less than a year. Secondly, even if the initial motive was to create solutions for business continuity by replacing the current arrangements with various technological innovations, entrepreneurs are convinced that many elements from this substitution will remain, which will continue to cause changes in supply chain services.

The door for virtual and hybrid events is opened, this fact confirms CMX (Community for Online Community Professionals) the report where $80 \%$ of the respondents stated that virtual events are becoming a more critical part of the organization's business strategy [34]. We can't ignore the fact that online participation must be a part of the future face-to-face events. The Traditional format of attending scientific conferences already before COVID-19 was questioned by the communities due to the large carbon footprint associated with the international flights, low accessibility for wide set of researchers including the persons with disability and those with limited resources or having caring and family concerns [27]. The positive impact of the virtual and hybrid events on the environment, the accessibility providing the learning opportunity for a greater number of researchers, the possibility to attract leading scientists who are more likely to accept the invitations because the time commitment is significantly less [35] the lower costs makes digital formats more and more attractive. "5G TECHRITORY” organizers point out that all type of the events will continue to develop in the future but will be more segmented and rational.

\section{CONCLUCIONS}

The hybrid event phenomena became a "new normal" of our everyday life, opening the new opportunities, but at the same time creating new challenges for the meeting and the event industry stakeholders.

The development of the meeting and the event industry is tightly connected with the adoption of new technologies to raise competitiveness. COVID-19 restrictions forced the industry to find new ways to organize interregional and international events and find the ways out of the sudden crisis. The majority of the industry had to make a pivot in 2020 and was forced to cover the technological adoption gap and build digital meeting solutions in their overall strategies within a very short period of time. Fast and unplanned investments in 2020 hit the financial stability of the service providers, the lasting lockdown and uncertainty aggravates the situation even more. For the events mostly already developed platforms were adopted, but for the 
online activities: combinations of online registration, event webpage and multimedia projections.

Industry members contrive experiencing such a rapid digital transformation, but point out the necessity of the specific digital knowledge and skills improvement, the need of the professional specialists to operate in digitalized reality. Internet speed and coverage, access to the advanced technical equipment, professional and experienced staff are named to be the biggest challenges. Industry members predict: the events will be held mostly online or hybrid in future either, although the onsite events give more specific atmosphere and positive memories. Face-to-face events will return, but with the element of online participation. Both the organizers and the participants will assess the need for travel more carefully. Although the organisation of virtual and hybrid events in most of the cases require the same budgets as face-to-face, many of them will stay in digital or phygital environment.

This research identifies the critical factors of technology use in the meeting and event industry, clear up which technologies were the most popular in the meeting and event industry before and will stay after COVID-19, how willing and ready are the event organizers to continue the implementation of digitalization in the event organization process in Latvia. Results acquired are not state specific and are applicable to the other states of the Baltic region or elsewhere with similar industry structure and development level. However, it encourages for deeper investigations, especially implementing new digital and online (or hybrid) event organisational business models in the industry in relation to the competitiveness of the hospitality industry. After such a rapid digital transformation part of the traditional business tourism services (e.g. hotel rooms, conference halls, catering, mobility and incentive travel etc.) are not used so extensively any more - what does these changes mean for relates industries within the supply chain. Another direction for further research includes challenging the digital gap of employees and other technological advances based on the specific industry needs. What other changes will bring transformation to digital destination and what skills and knowledge should be improved to operate virtual and hybrid meetings, to investigate the behaviour of delegates, to detect the tools for deeper engagement of the participants, to explore the financial models for the successful business development in digitalized environment.

Hall quoted Dietvorst that all tourism related events have space and time attributes attached to them [34], but this is challenged with digital events, where traditional destinations turns into a virtual venue, but the flow of visitors does not follow: sharing the same time, but not place.

\section{Acknowledgements}

The authors express their gratitude to Latvia Convention Bureau, Association of Latvian Travel Agents and Operators and Association of Hotels and Restaurants of Latvia for the support in distributing the survey and involvement of industry. Research has contributed to the post-doctoral project No. 1.1.1.2/VIAA/1/16/100.

\section{REFERENCES}

[1] T. Rodgers, Conferences and Conventions: A Global Industry (3 edition). London \& New York: Routledge, 2013.

[2] J. Calvin, and L. ShiNa, "The economic importance of meetings and conferences: A satellite account approach,” Annals of Tourism Research, vol. 52, pp. 117-133, May 2015. https://doi.org/10.1016/j.annals.2015.03.004

[3] J.S. Olson, Historical dictionary of European imperialism. Greenwood, 1991.

[4] R.C. Ford, and W. C. Peeper, "The past as prologue: predicting the future of the convention and visitor bureau industry on the basis of its history,” Tourism Management, vol. 28, no. 4, pp. 1104-1114, August, 2007. https://doi.org/10.1016/j.tourman.2006.07.002

[5] D. Getz and S.J. Page, "Progress and prospects for event tourism research,” Tourism Management, vol. 52, pp. 593-631, February, 2016. https://doi.org/10.1016/j.tourman.2015.03.007

[6] R. Davidson, Business Events. London: Routledge, 2019.

[7] The World Tourism Organization, “Glossary of Tourism terms”, 2021. Available: https://www.unwto.org/glossary-tourism-terms. [Accessed: March 19, 2021].

[8] J. Allen, R. Harris, L. Jago, and A. Veal (Eds.), Events beyond 2000: Setting the agenda. Proceedings of the conference on event evaluation, July 13-14, 2020, pp. 154-161. Sydney: Research and Education.

[9] J. Swarbrooke and S. Horner, Business travel and tourism. Oxford: Butterworth-Heinemann, 2001.

[10] D. Getz, "Event tourism: Definition, evolution, and research. Tourism management," Tourism management, vol. 29, no. 3 , pp.403-428, June 2008. https://doi.org/10.1016/j.tourman.2007.07.017

[11] D. Getz, Event studies. In S. Page, \& J. Connell (Eds.), The Routledge handbook of events. Oxon: Routledge, 2012.

[12] B. McKercher, "Towards a taxonomy of tourism products," Tourism Management, vol. 54, pp. 196-208, June 2016. https://doi.org/10.1016/j.tourman.2015.11.008

[13] D. Buhalis and R. Law, "Progress in information technology and tourism management: 20 years on and 10 years after the internetthe state of eTourism research,” Tourism Management, vol. 29, pp. 609-623, August 2008. https://doi.org/10.1016/j.tourman.2008.01.005

[14] J. Navio-Marco, L. Ruiz-Gomez and C. Sevilla-Sevilla, "Progress in information technology and tourism management: 30 years on and 20 years after internet - revisiting buhalis \& law's landmark study about eTourism,” Tourism Management, vol. 60, pp. 460470, December 2018. https://doi.org/10.1016/j.tourman.2018.06.002

[15] Union of International Associations, "International Meetings Statistics Report”, $2020 . \quad$ [Online]. Available: https://uia.org/publications/meetings-stats . [Accessed: March 19, 2021].

[16] International Congress and Convention Association, "2019 ICCA Statistics Report: Country \& City Rankings”, June 2020. [Online]. Available: https://www.the-iceberg.org/research/2019-iccastatistics-report-country-city-rankings//. [Accessed: March 19, 2021].

[17] M. Sikosek, "A Review of Research in Meetings Management: Some Issues and Challenges," Academica Turistica - Tourism and 
Innovation Journal, vol. 5, no. 2, p. 61-76, 2012. Available: Ideas, https://ideas.repec.org/. [Accessed March 15, 2021].

[18] O. Mubin, F. Alnaijar, A. Shamail, S. Shahid and S. Simoff, "The new norm: Computer Science conferences respond to COVID-19," Scientometrics, vol. 126, p.1813-1827, Nov. 2020. https://doi.org/10.1007/s11192-020-03788-9

[19] J. Wen, M. Kozak, S. Yang and F. Liu, “COVID-19: potential effects on Chinese citizens' lifestyle and travel,” Tourism Review, vol. 76 No. 1, pp. 74-87, 2020. https://doi.org/10.1108/TR-03$\underline{2020-0110}$

[20] T.M. Wut, J. Xu and S. Wong, "Crisis management research (1985-2020) in the hospitality and tourism industry: A review and research agenda,” Tourism Management, vol. 85, August 2021. https://doi.org/10.1016/j.tourman.2021.104307

[21] V. Kaushal and S. Srivastava, "Hospitality and tourism industry amid COVID-19 pandemic: Perspectives on challenges and learnings from India," International Journal of Hospitality Management, vol. 92, January 2021. https://doi.org/10.1016/j.ijhm.2020.102707

[22] M. Breier, A. Kallmuenzer, Th. Clauss, J. Gast, S. Kraus and V. Tiberius, "The role of business model innovation in the hospitality industry during the COVID-19 crisis," International Journal of Hospitality Management, vol. 92, January 2021. https://doi.org/10.1016/j.ijhm.2020.102723

[23] H. Pang, D. Wiercigroch and A. Sriharan, "Re-thinking conferences in medicine: opportunities and challenges of virtual delivery,” Can J Physician Leadersh vol. 7, no. 1. P. 52-56, 2020. https://doi.org/ 10.37964/cr24728

[24] A. Margolis, J.T. Balmer, A. Zimmerman and A. LópezArredondo, "The Extended Congress: Reimagining scientific meetings after the COVID-19 pandemic,” MedEdPublish, vol. 9, no. 1 , p. 128 , June, 2020. https://doi.org/10.15694/mep.2020.000128.1

[25] M.R. Fulcher, M.L. Bolton, M.D. Millican, M.J. Michalska-Smith, J.P. Dundore-Arias, J. Handelsman, J.L. Klassen, K.C. MilliganMyhre, A. Shade, B.E. Wolfe, and L.L. Kinkel, "Broadening Participation in Scientific Conferences during the Era of Social Distancing," Scientific Life, vol. 28, no. 12, pp. 949-952, Sept. 2020. [Online]. Available: Trends in Microbiology, https://www.cell.com/trends/microbiology/home . [Accessed March 16, 2021], https://doi.org/10.1016/j.tim.2020.08.004

[26] A. Margolis, "How to Migrate from a Traditional Live Congress to [36]
[Online]. Available: http://www.acehp.org/p/bl/et/blogaid=613. [Accessed: March 19, 2021].

[27] J.V. Milić, B. Ehrler, C. Molina, M. Saliba and J. Bisquert, “Online Meetings in Times of Global Crisis: Toward Sustainable Conferencing”, ACS Energy Lett., vol. 5, no. 6, p. 2024-2026, May, 2020. Available: ACS Publications https://pubs.acs.org/doi/full/10.1021/acsenergylett.0c01070. [Accessed: March 19, 2021]. https://doi.org/10.1021/acsenergylett.0c01070

[28] Z. Hameed, Y. Tanidir, N. Naik, J. Yuen-Chun Teoh, M. Shah, M.L. Wroclawski, A.B. Kunjibettu, D. Castellani, S. Ibrahim, R. D. Silva, B. Rai, J. Rosette, Rajeev, V, Gauhar and B. Somani, "Will "Hybrid" Meetings Replace Face-To-Face Meetings Post COVID-19 Era? Perceptions and Views From The Urological Community,” Urology, 2021. https://doi.org/10.1016/j.urology.2021.02.001

[29] E.C. Buxton, E.C. Burns, and James E. De Muth, "Professional Development Webinars for Pharmacists,” American Journal of Pharmaceutical Education, vol. 76, no. 8, p.1, 2012. [Online]. Available: https://www.ajpe.org/. [Accessed: March 19, 2021].

[30] N. Dua, M. Fyrenius, D.L. Johnson and W. H. Moos, “Are inperson scientific conferences dead or alive?”, vol. 00, p.1+, January 2021. [Online]. Available: Faseb, https://faseb.onlinelibrary.wiley.com/. [Accessed March 15, 2021], https://doi.org/10.1096/fba.2020-00139

[31] E. Albeniz, P. Roson, L. Hernandez-Villalba and M. Enguita, "Stay Connected and Up To Date. GI Meetings and Seminars and the Coronavirus Disease 2019 Pandemic," Gastrointestinal Endoscopy, vol. 00, no. 00, p.1-5, Nov. 2020. https://doi.org/10.1016/j.tige.2020.11.001

[32] J. Hoods, T. Pakarinen, "From hybrid events to the next generation - interactive virtual events," M.S. thesis, Lahti University of Applied Sciences. Lahti, Finland, 2018.

[33] H. Hajibaba, U. Gretzel, F. Leisch, and S. Dolnicar, "Crisisresistant tourists," Annals of Tourism Research, vol. 53, no. 4, p.46-60, July, 2015. https://doi.org/10.1016/j.annals.2015.04.001

[34] CMX, “The 2021 Community Industry Report,” 2021. [Online]. Available: https://cmxhub.com/community-industry-report-2021/ [Accessed: March 19, 2021].

[35] C.M. Hall, Spatial analysis: A critical tool for tourism geographies. London: Routledge handbook of tourism geographies, 2017. 